\title{
CYSTICERCOSIS IN THE ORAL CAVITY: A CASE REPORT WITH REVIEW OF LITERATURE
}

\author{
G. Prabhakar1, G. V. S. S. D. Deepak Chakravarthy²
}

\section{HOW TO CITE THIS ARTICLE:}

G. Prabhakar, G. V. S. S. D. Deepak Chakravarthy. “Cysticercosis in the Oral Cavity: A Case Report with Review of Literature". Journal of Evolution of Medical and Dental Sciences 2014; Vol. 3, Issue 20, May 19;

Page: 5381-5383, DOI: 10.14260/jemds/2014/2601

\begin{abstract}
Cysticercosis is caused by the larval stage of Taenia Solium. A middle aged woman presented with a painless solitary nodular swelling on left lateral border of the tongue. Fine needle aspiration cytology revealed only blood elements. Excision biopsy was done and sent for histopathological examination which revealed larvae of the pork tapeworm (Cysticercosis). Cysticercosis in human tissues is unusual. Oral cysticercosis, especially the involvement of tongue is very rare in humans.
\end{abstract}

KEYWORDS: Cysticercosis, oral cavity, Pork tapeworm.

INTRODUCTION: The adult Taenia Solium, or pork tapeworm, lives in the small intestine of man, its definitive host. Infestation by Taenia Solium is common in areas where pig breeding is not controlled and sanitation is inadequate. Latin America, Southern Africa, India, Southeast Asia and Eastern Europe are the most frequent locations of occurrence. ${ }^{1}$ Cysticercosis is the larval stage of the tape worm. Taenia Solium found in tissues whereas the adult worm form is found in the intestines. The eggs, after ingestion of contaminated food, release larvae in the intestine, which penetrate the intestinal wall and migrate to various sites with an affinity for neck, trunk, subcutaneous tissues and brain. ${ }^{2}$ Oral cysticercosis is a rare event, and it represents difficulty in clinical diagnosis. ${ }^{3}$ The most frequent sites of cysticercosis occurrence are subcutaneous layers, brain, muscles, heart, liver, lungs, and peritoneum.4, 5 Here we report a case of oral Cysticercosis in a middle aged woman.

CASE REPORT: A 42 year old woman presented with a swelling on the left lateral border of the tongue to the outpatient department of ENT. The patient reported that the lesion was present since one year and it was painless. Intra oral examination revealed that the lesion was solitary nodular swelling on left lateral border of the tongue measuring $2 \mathrm{X} 2 \mathrm{~cm}$. A clinical differential diagnosis of mucocele, sialocyst, lymphangioma and minor salivary gland tumor was given. The lesion was aspirated and Fine needle aspiration cytology (FNAC) report showed only blood elements. Surgically the lesion was excised under local anesthesia, and sent for histopathological examination.

Microscopic examination revealed a capsule of fibrous connective tissue surrounding a cystic cavity, which contained the Cysticercus cellulosae, the Taenia Solium larval form (Figure 1). The capsule showed intense inflammatory infiltrate, consisting mainly of lymphocytes and plasma cells. No areas of dystrophic calcification were seen. Final diagnosis of cysticercosis was made histopathologically.

DISCUSSION: Taenia Solium is usually acquired by the ingestion of eggs in the food contaminated with feces. Humans are the only definite host, with pigs serving as intermediate hosts only. The larvae hatch in the small intestinal lumen and penetrate the wall to reach their site of encystations 
commonly subcutaneous tissue, skeletal muscle, brain and head and neck region. Cysticercosis is uncommon in the oral cavity of humans where they appear as cystic nodules that may rupture and heal uneventfully. ${ }^{2}$ Cysticercosis of the oral cavity is rare only a handful of cases have been reported earlier. ${ }^{6}$

Cysticercosis may involve many parts of the body including the subcutaneous tissues, eye, liver, peritoneum, heart, and lungs. However, the skeletal muscle is most commonly affected; the most common site of severe symptomatic infection is the CNS. ${ }^{7}$ The most common complaint of the patients is swelling. Pain is not a frequent feature unless secondarily infected. Most oral presentations are in the form of painless, well-circumscribed, soft swellings that may mimic fluctuant lesions like mucocele. ${ }^{7}$ The present case showed similar clinical features like painless swelling, well circumscribed and soft in consistency.

Routine sections stained with hematoxylin and eosin may be all that is required for diagnosis, although in later stages only an inflammatory response to dead larvae may be seen. Fine needle aspiration cytology (FNAC) can also aid in diagnosis but it is very difficult to confirm the diagnosis. Studies have demonstrated that parts of the parasite have been identified in $45 \%$ to $100 \%$ of the aspirates, particularly when the aspirated material showed a speck of pearly white content that was confirmed to be the larva in acute and chronic inflammatory background by microscopic examination. In our case, the aspirate revealed only red blood cells.

Currently other diagnostic tools as radiologic imaging and serology can be used. Besides normal radiographic examination other modalities of imaging exams are very effective in the detection of cysticercosis, as computerized tomography and magnetic resonance. Saran et al ${ }^{8}$ proposed the use of fine-needle aspiration cytology, which identifies the tegument layer of the larva, to help the clinician in planning the treatment. But, the present case showed only blood elements in FNAC. Immunodetection of cysticercosis can be achieved in sera, cerebrospinal fluid and saliva, by ELISA (enzyme-linked immunosorbent) assay or EITB (enzyme-linked immunoelectrotransfer blot), ${ }^{4}$ but it is important to consider that individuals living in an endemic area may have antibodies because of an exposure instead of an established infection. Sanchez et al, ${ }^{9}$ performing EITB in patients from endemic areas with brain lesion compatible with neurocysticercosis, found a similar proportion of seropositive and seronegative groups. Every case of oral cysticercosis should be thoroughly investigated to determine the involvement of multiple foci, since there is a high incidence of such feature. ${ }^{10}$

The diagnosis of oral cysticercosis is made by direct histological examination. In every case, detailed study should be done in order to exclude the presence of the parasite in other sites. MRI and computerized tomography (CT) may be used to evaluate CNS involvement. Even in an endemic area, tongue and lip is a rare site of involvement in cysticercosis. Confirmative diagnosis of cysticercosis is only made by histopathological examination. In our present case diagnosis was made by histopathological examination only. However; FNAC sections studied showed only sheets of red blood cells.

CONCLUSION: Cysticercosis of the oral cavity is rare. It is important to consider the diagnosis of cysticercosis in oral solitaire nodular lesions presenting in patients living in an endemic area. This case emphasizes the role of an ENT surgeon in the detection of a disease that can have more serious involvement, as well as the importance of routine histological examination. 


\section{REFERENCES:}

1. Prabhu, S.R. Oral diseases in the tropics. Oxford, Oxford University Press, 1992:126-129.

2. Jay A, Dhanda J, Chiodini PL, Woodrow CJ, Farthing PM, Evans J, Jager HR. Oral cysticercosis. Br J Oral Maxillofac Surg. 2007; 45(4): 331-4.

3. Sathe NU, Acharya RG, Patil M, Bhatia A, Chiplunkar D. An unusual case of labial cysticercosis with a natural history. Natl J Maxillofac Surg. 2011; 2(1): 100-2.

4. Flisser A, Plancarte A, Correa D. New approaches in the diagnosis of Taenia solium cysticercosis and taeniasis. Ann Parasit Hum Comp, 1990; 65:95-98.

5. Wortman P.D. Subcutaneous cysticercosis. J Amer Acad Derm, 1991; 25: 409-414.

6. De Souza PE, Barreto DC, Fonseca LM, de Paula AM, Silva EC, Gomez RS. Cysticercosis of the oral cavity: report of seven cases. Oral Dis. 2000; 6(4): 253-5.

7. Garcia HH, Del Brutto OH. Taenia solium cysticercosis. Infect Dis Clin North Am. 2000; 14:97119.

8. Saran RK, Rattan V, Rajwanshi A, Nijkawan R. \& Gupta SK. Cysticercosis of the oral cavity: report of five cases and a review of literature. Int J Paediat Dent, 1998; 8: 273-278.

9. Sanchez AL, Lindback J, Schantz PM. A population-based, case control study of Taenia solium taeniasis and cysticercosis. Ann Trop Med Parasit, 1999; 93: 247-258.

10. Lustmann J, Copelyn M. Oral cysticercosis. Review of the literature and report of 2 cases. Int J Oral Surg, 1981; 10: 371-375.

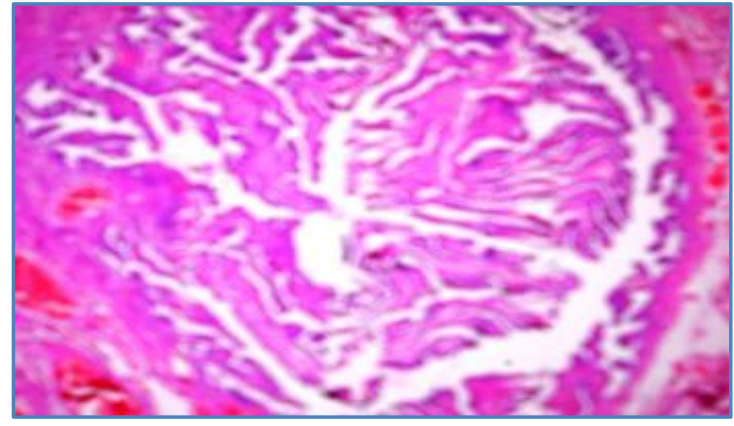

\section{Fig. 1: Taenia Solium larval form in cystic cavity surrounded by capsule of fibrous connective tissue. (H\&E, X40)}

\section{AUTHORS:}

1. G. Prabhakar

2. G. V.S. S. D. Deepak Chakravarthy

\section{PARTICULARS OF CONTRIBUTORS:}

1. Professor, Department of ENT, Alluri Sitarama Raju Academy of Medical Sciences.

2. Assistant Professor, Department of ENT, Alluri Sitarama Raju Academy of Medical Sciences.

\section{NAME ADDRESS EMAIL ID OF THE CORRESPONDING AUTHOR: \\ Dr. Prabhakar, \\ Professor of ENT, Alluri Sitarama Raju Academy of Medical Sciences, \\ Eluru. \\ Email: avis.reddy@gmail.com}

Date of Submission: 04/05/2014.

Date of Peer Review: 05/05/2014.

Date of Acceptance: 09/05/2014.

Date of Publishing: 13/05/2014. 